\title{
Impact of Pyrotechnics over the Architectonic Heritage
}

\author{
Angel T. Lloret, ${ }^{1}$ Sandra Sendra, ${ }^{2,3}$ Jaime Lloret, ${ }^{3}$ Miguel Louis Cereceda, ${ }^{1}$ and Jesus Alba ${ }^{4}$ \\ ${ }^{1}$ Universidad de Alicante, Carretera San Vicente del Raspeig, s/n, 03690 San Vicente del Raspeig, Spain \\ ${ }^{2}$ Signal Theory, Telematics and Communications Department (TSTC), Universidad de Granada, C/Periodista Daniel Saucedo Aranda, \\ s/n, 18071 Granada, Spain \\ ${ }^{3}$ Integrated Management Coastal Research Institute, Universitat Politècnica de València, C/Paranimf, No. 1, Grao de Gandia, \\ 46730 Gandia, Spain \\ ${ }^{4}$ Centre for Physics Technologies, Universitat Politècnica de València, Av. de Los Naranjos, s/n, 46022 Valencia, Spain
}

Correspondence should be addressed to Jaime Lloret; jlloret@dcom.upv.es

Received 31 May 2017; Accepted 24 July 2017; Published 29 August 2017

Academic Editor: Taesun You

Copyright (c) 2017 Angel T. Lloret et al. This is an open access article distributed under the Creative Commons Attribution License, which permits unrestricted use, distribution, and reproduction in any medium, provided the original work is properly cited.

\begin{abstract}
The use of pyrotechnics near to the historical heritage such as walls, facades, church, or fortifications of a city is nowadays a topic of discussion. There is not a clear legislation about the use of pyrotechnics near to these buildings and how they can be affected by the expansive wave generated by the use of harquebusiers, fireworks, and cannons during the simulation of a battle. For this reason, this paper presents some practical tests that measure the vibroacoustic effect when these types of pyrotechnics are used near to the architectonical heritage. In order to collect these data, we have used several sound level meters and accelerometers placed on two different scenarios. The first one was placed near to the beach and the other one was placed in a building of a narrow alley. The tests were carried out during the festival of Moors and Christians of Villajoyosa (Spain) which is a famous festival. Along these tests, we reproduce the worse cases that may affect the building, using harquebusiers shots, fireworks, and cannons shots. Results show that the house placed near to the beach does not suffer important vibroacoustic impacts. However, the old building placed in the alley is very affected.
\end{abstract}

\section{Introduction}

Along the Mediterranean coast, we can find hundreds of fortifications, walls, castles, and watchtowers for the defense of their territories. These elements, built around the XIV and XVIII centuries, are nowadays part of the historical heritage and, therefore, we should plead for their conservation and protection.

Due to the importance of historical events, many cities where these architectonical elements are located generally hold parties that reproduce some of the battles to commemorate them. These recreational activities are usually carried out in the historical center of the city, taking advantage of the beauty of the landscape which is, at the same time, a tourist attraction that brings great economic benefits to them $[1,2]$.

The reproduction of these battles is often done using different types of pyrotechnics, ranging between fireworks, firecrackers, handguns, and small guns. The explosion and the deflagration of this type of pyrotechnic generally generate a displacement in form of mechanical wave that impact the facades. Nevertheless, in the related literature, its effect on the old buildings has not been quantified.

In order to quantify these effects, distributed sensor networks can be used over throughout the monitoring area. A sensor or transducer [3] is an electronic device which is capable of translating the variation of a physical parameter into electrical signals that are processed by the sensor nodes. Many of these nodes allow us to implement a wireless sensor network (WSN) [4]. WSNs are nowadays a hot topic due to their wide range of applications. They can be used for environmental monitoring, military applications, precision agriculture, domestic applications or tracking people and objects, and buildings monitoring [5]. A set of sensors deployed in a home can give us many types of information such as the structural aging, fatigue and damage materials, gas leaks, fires, inadequate humidity, and temperature values. 
An exhaustive measurement process can provide valuable information to the researchers for preventing building problems [6] and allow us to take decisions about our habits, so as not to worsen the situation of a building or to maintain its level of conservation, as the case of the historical heritage. Analyzing the existing literature, we can affirm that there are very few initiatives related to the deployment of sensor networks for the monitoring of historical heritage. However, the sensors are widely used in the processes of surveillance and conservation of art [7] and fresh [8].

Therefore, the effect of the use of pyrotechnic near to these buildings must be monitored and quantified. This paper presents a practical study to determine the impact that harquebuses and fireworks can generate on the historical heritage. In order to do it, we have selected two different scenarios where these kinds of pyrotechnics are used. From these tests, we measure both the acoustic and vibration effect over the buildings. On the one hand, the acoustic impact can be understood as the magnitude of mechanic wave that impacts the building. Because these waves displace the air present in the medium, the building registers some small structural movements. To measure these, we can use accelerometers placed along the surface under study and then process the data to extract the vibration levels. With these 2 parameters, we can evaluate the vibroacoustic effect as a function of the facade height. The selected city is Villajoyosa (Spain), which is famous because of its festival of Moors and Christians. To measure these effects, we used several sound meters and vibration sensors installed on the façade. For the first scenario, which is a house placed near to the beach, three different sound sources were used: cannons, shots from harquebusiers, and shots from boats. The second scenario is an old building placed in a narrow alley. In this case, 6 harquebuses and blunderbusses were used to perform the shots. With the results, we sketch the maps of the acoustic effect and the vibration effect over the facade. The results show that the impact over the facade depends on the place where there is a shot and the building height.

The rest of this paper is structured as follows. Section 2 presents several related papers where researchers performed some studies about the impact of acoustic waves over buildings. Section 3 explains the features of the scenarios used to carry out the tests, as well as the tools, sensors, materials, and sound meters used to perform our tests. Section 4 defines the experiments carried out and their results. Finally, Section 5 shows the conclusion and future research line to continue our research.

\section{Related Works}

Generally, WSNs in buildings are used for monitoring indoor variables, for taking care of their inhabitants [9], and for developing applications related to Internet of Things (IoT) [10]. There are very few practical studies about old buildings monitoring. We have only found few old studies about the use of harquebuses and some acoustic impact analyses on buildings related to the insulation characteristics of dwellings to ensure the well-being of its inhabitants [11]. This section shows some previous work in which the authors have analyzed the effect of the sound pressure on buildings.

Firstly, the acoustic characteristics of harquebuses and blunderbusses used in this type of festivities are analyzed. The work was carried out by Marco Sanjuán in 1996 [12]. He performed several measures in relation to the sound levels of these types of weapons. The study only covered certain explosives and weapons' calibers. However, these results offer us a basic indicator to start our study of the received sound pressure over the buildings.

Regarding the deployment of networks in buildings, Bennett et al. [13] presented a sensor network deployed in a building to monitor the structural movement of the buildings generated by the passage of undergrounds and trams located in London and Prague. The document identifies the critical factors that should be taken into account in the design of a WSN in terms of energy constraints and communication issues between nodes. Throughout the work, the authors identified the problems in the deployment of the network in both locations and try to demonstrate with their tests the feasibility and advantages of using WSNs in underground environments.

Späh et al. [14] conducted a study about the impact of acoustic waves on houses made of wood. In this case, the authors did not use a sensor network to perform their measurements, but they show the effect suffered by these types of dwellings. In fact, these measures were carried out under the AcuWood project, whose main objective was to find technical descriptors for different sound sources taking into account construction traditions and cultural differences of several European countries. In order to obtain the results, the authors used correlation techniques to relate the different technical descriptors of the different types of constructions with the obtained acoustic results. The results can be used as a reference model in the evaluation of certain noise sources.

Finally, Yu and Kang [15] presented a study to characterize the effects of the acoustic impact on different materials used in architecture. The study was conducted in various houses with different structural characteristics. For each building, the authors compared different types of materials commonly used in wall covering and different types of glazing. The results showed the importance of considering the environmental sustainability of acoustic materials when building a house.

There are very few works where the effects of vibration are contemplated, in addition to the acoustic impact. In fact, the only work we have found is the one presented by Klos in [16]. In this case, the author carried out a study that analyzed the vibroacoustic response of buildings due to exposure to a sonic pump. In the experiment, more than 100 transducers were installed in various bedrooms of a house. In addition, accelerometers were randomly placed on walls, windows, and ceilings at rooms and around the house. With the results, the author was able to characterize the response of the different materials in terms of reverberation time and isolation level.

We have not found any study that relates the use of gun replicas in this type of centenary celebrations and its effect on the cultural built heritage. We believe that it is important to keep these celebrations. Moreover, we also believe that it 


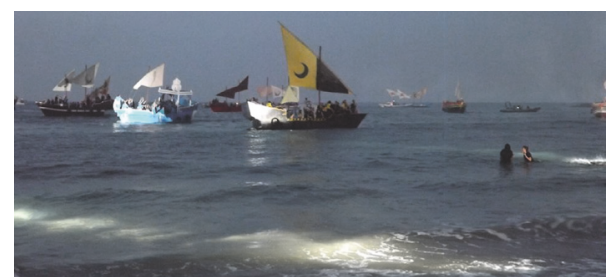

FIGURE 1: Moorish troops navigating near the coast.

is necessary to preserve the monumental remains and our historical heritage and, therefore, we wish to analyze and characterize how historical buildings may be affected by the use of these types of fireworks in order to propose corrective measures.

\section{Scenario and Material Description}

In order to carry out our test bench, two different scenarios have been selected. The first scenario is placed on the beach where it recreated the night battle during which the Moorish troops land on the beach and the Christian troops try to repeal them. The second scenario has been specially selected for reproducing the worst case, where Moorish and Christian weapons are shot near the old buildings. For each case, different materials are used. This section explains the details of each scenario and the material used.

3.1. Scenario 1: Night Battle. The night battle takes place throughout the night. During the night, the Moorish troops navigate with their ships near the coast and make different shots towards the coast (Figure 1).

These shots are acoustically imperceptible due to the distance (Figure 2(a)). In response, from the sand, several shots are fired by cannons (Figure 2(b)) and harquebusiers (Figure 2(c)). Cannons and harquebusiers are perceived from homes and, therefore, we want to measure the acoustic impact on them.

In the sand of the beach, we can distinguish 2 different zones. There are 3 cannons (see Figure 3) whose characteristics and dimensions are shown in Table 1. Cannon is a hollow piece of metal or another material that forms a cane, used in artillery, which has great length with respect to its caliber. Formerly, they were used to shoot bullets and shrapnel but they serve nowadays to reproduce shots in celebrations exclusively using gunpowder that produces great blares. In addition, we also distinguish a battle area where the harquebusiers with their guns are placed. Figure 4 shows the battle area and the cannons' area with the distance up to the position of measurement.

3.2. Scenario 2: Shots in the Narrow Alley. The second part of these tests is performed in an uninhabited house placed in a pedestrian street in the historic city center. The historic city center contains many historical sights of the city. These include defensive walls built between 1551 and 1565 to repel Berber attacks, a watchtower built around the 15th century, and several colorful and old buildings that characterize this
TABLE 1: Size of cannons.

\begin{tabular}{lccc}
\hline & Length of cannon & Inner length of cannon & Caliber \\
\hline Cleopatra & $85 \mathrm{~cm}$ & $78 \mathrm{~cm}$ & $12 \mathrm{~cm}$ \\
Art Mora & $106 \mathrm{~cm}$ & $68 \mathrm{~cm}$ & $18 \mathrm{~cm}$ \\
Art Islam & $60 \mathrm{~cm}$ & $46 \mathrm{~cm}$ & $11 \mathrm{~cm}$ \\
\hline
\end{tabular}

city. Figure 5 shows a section of Villajoyosa city (in Alicante province, Spain) and the area of the second scenario where the tests have been carried out.

The building selected for the second test is an old rectangular-base building. The foundation of this dwelling sits exactly at the base of the dwelling, while the structural support is made in load walls which have thick walls above normal. The structural system of the surface based on the walls of load has been made with the masonry mortar. The load walls that form the outer faces have a mortar of cement and sand and it is covered by a typical plaster of concrete and sand. The load-bearing thickness walls decrease as the height of the building increases. Finally, the building presents a staircase that communicates with the floors. Figure 6 shows the image of the building where the measurements were taken.

Figure 7 shows the scale drawing of the scenario where the tests are performed. This image also shows the position of the harquebusiers and the positions where the sound level meters and vibration sensors are located. Each harquebusier is identified as "Harquebusier_ $X$ " where $X$ indicates the harquebusier. The distance between harquebusiers is $2 \mathrm{~m}$ and the distance between the building and harquebusiers is $3 \mathrm{~m}$. Sound level meters are identified as "Sono_Y" where $Y$ indicates the device. This nomenclature is used in the rest of the paper.

Regarding the location of the sensors, the 4 sound level meters (Sono_3, Sono_4, Sono_5, and Sono_6) are located inside the building, at 2 meters from the inside of the facade, window, or access door. With this distance we ensure that the reflections of the reflecting surfaces of the building do not affect the measurement records. Additionally, Sono_2 is used as dosimeter, that is, to measure vibrations. This dosimeter has been used to check some strange movement in the building which could jeopardize the integrity of the researchers and collaborators who were helping during the tests.

The vibration sensors take measurements of the three axes. They are fixed to the outside of the facade with a support that gives freedom of movement to the sensors. Figure 7 also shows the location of the vibration sensors by small red blocks. Finally, we can see that the section of surface that is monitoring comprises a space of $6 \mathrm{~m}$ height per $6 \mathrm{~m}$ width.

To perform the shots, 6 different weapons have been used. Table 2 shows the features of each weapon as well as their sizes and brands.

3.3. Materials and Tools. This subsection explains the features of the weapons, the features of the black gunpowder used with these weapons, and the instruments and sensors used to 


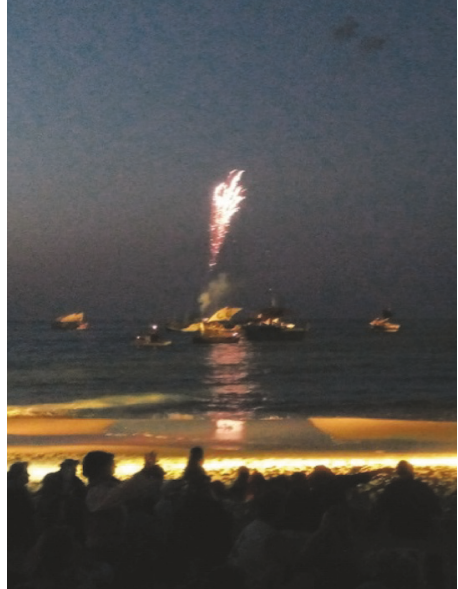

(a)

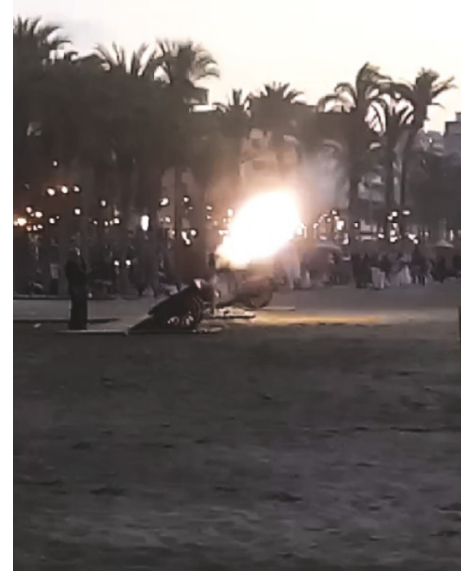

(b)

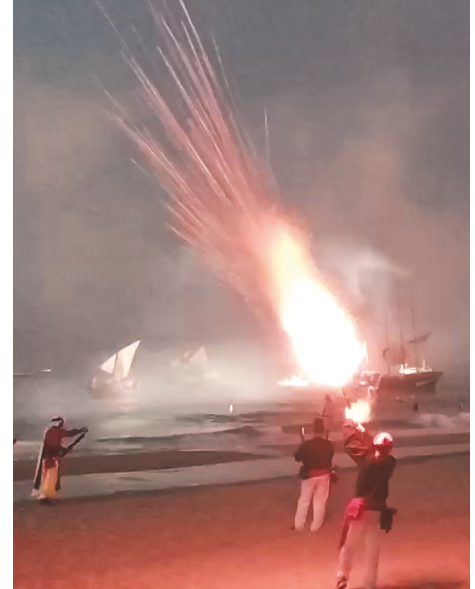

(c)

FIgURE 2: Different kinds of shots during the battle night.

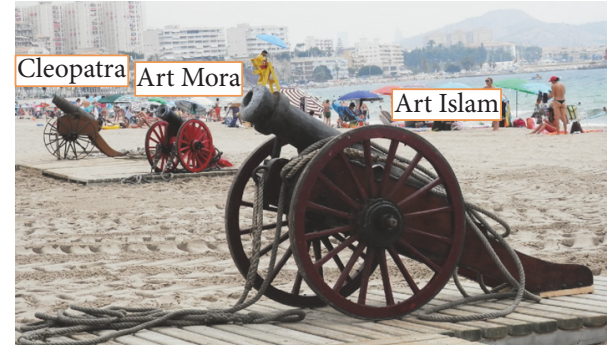

Figure 3: Cannons used in these tests.

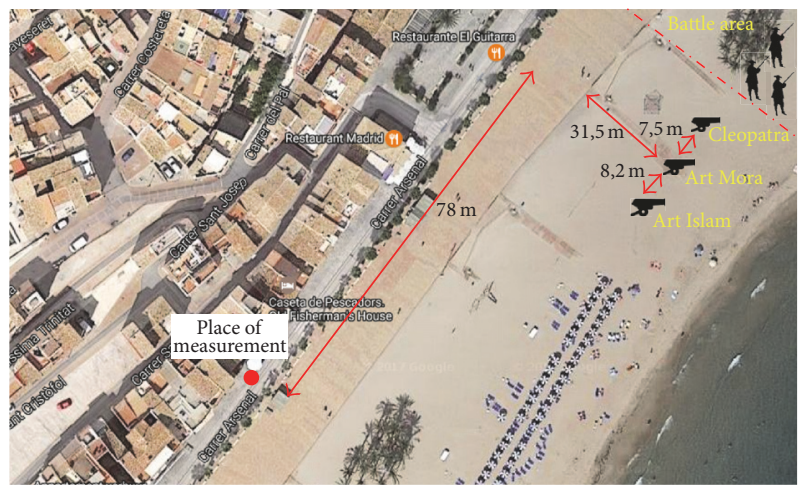

FIgURE 4: Position of cannons and harquebusiers in the beach.

take the measurements of the acoustic and vibration impact in both scenarios.

3.3.1. Weapons. During the replica of these centenarian battles, harquebusiers use firearms without bullets which generate a large flare (See Figure 8). Generally, harquebusiers use blunderbusses or harquebuses. Both are firearms with small differences between them.

Harquebus and blunderbuss are old firearms built with an iron barrel and a wooden box. A mechanical detonation

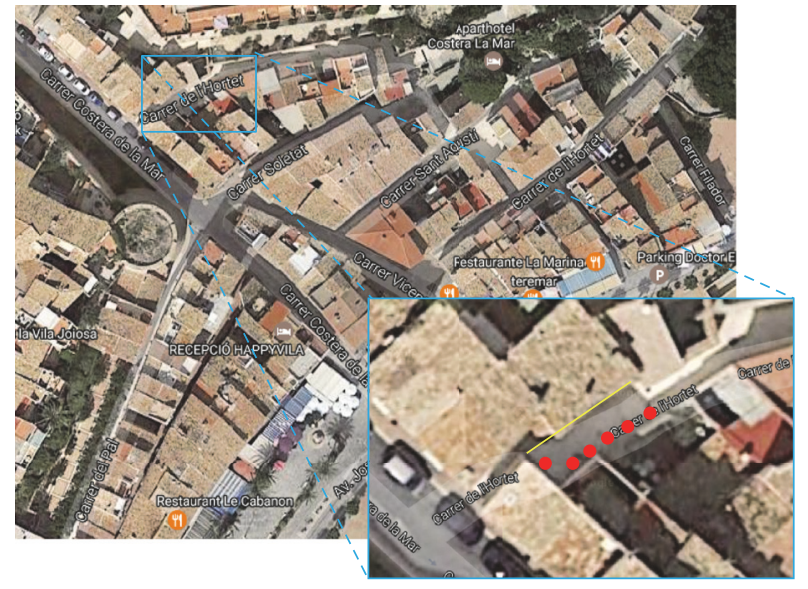

- Harquebusiers

Facade where measurements are performed

FIGURE 5: Location of the second scenario.

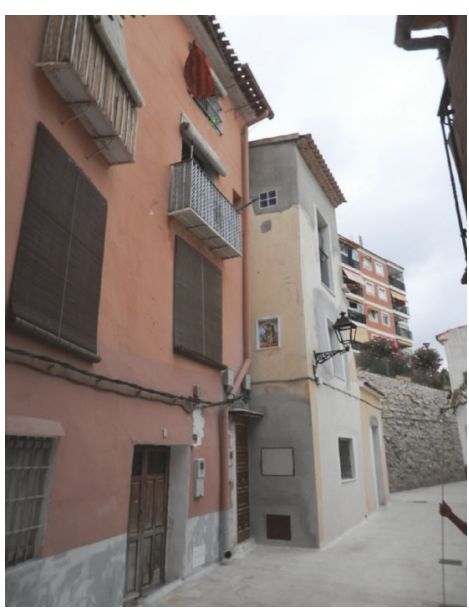

FIGURE 6: Real facade where measurements were taken. 
TABLE 2: Features of weapons used during these tests.

\begin{tabular}{lcccccc}
\hline & \multicolumn{5}{c}{ Harquebuses } \\
& 1 & 2 & 3 & 4 & 5 \\
\hline Kind of weapon & Muzzle-loading & Blunderbuss & Muzzle-loading & Muzzle-loading & Blunderbuss & Blunderbuss \\
Brand & BOPE & ARDESA & BOPE & GIL & BOPE & ARDESA \\
Caliber $(\mathrm{mm})$ & 62 & 62 & 28 & 28 & 60 & 62 \\
Barrel length $(\mathrm{cm})$ & 50 & 50 & 41 & 40 & 50 & 50 \\
\hline
\end{tabular}

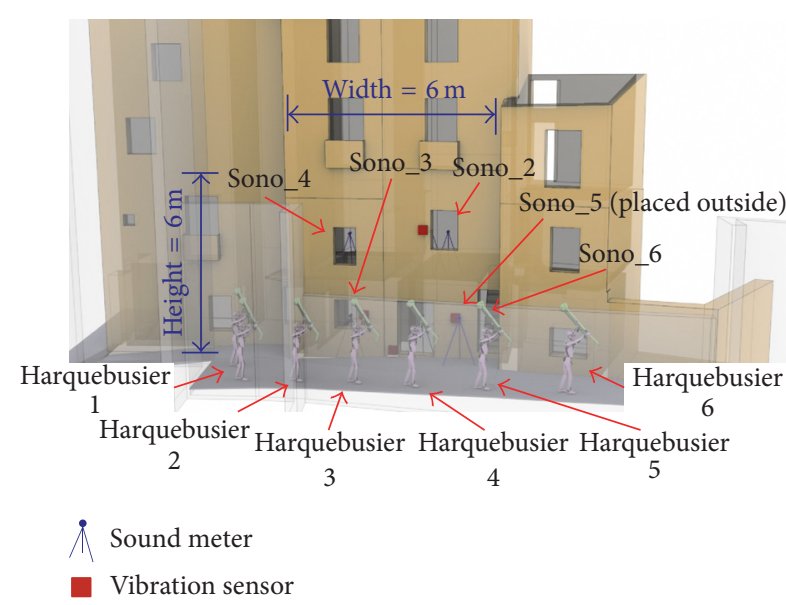

Figure 7: Position of harquebusiers, sound level meters, and vibration sensors.
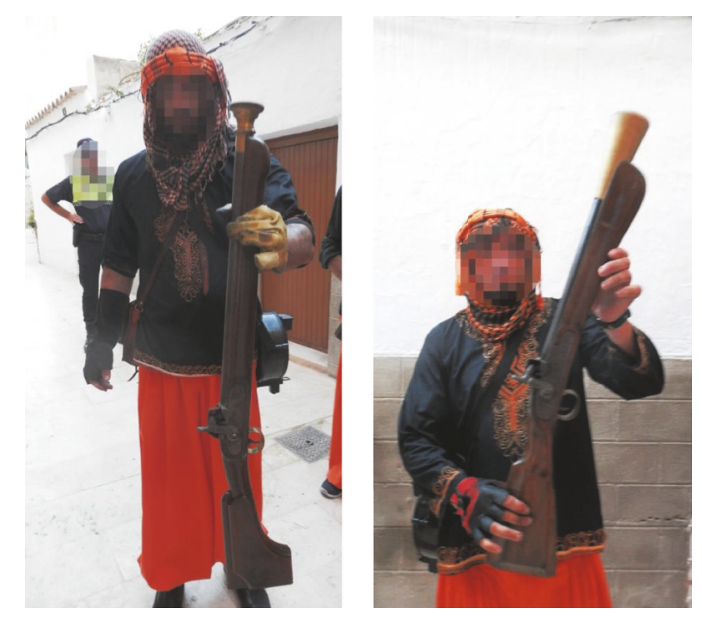

FIGURE 8: Harquebusier used in our tests.

system is used for firing these types of weapons. It consists of a mechanical actuator activated by a ball of a firing pin embedded in the chimney. This type of weapon was used by Moorish soldiers and Christians troops. The weapons are usually muzzle-loading. According to its construction and type of camera, the weapon can load from $15 \mathrm{~g}$ to $50 \mathrm{~g}$ of black gunpowder. The gun barrel has a flared appearance for easy loading. The name "harquebus" is due to the arched shape of the mouth that changed in blunderbuss to facilitate the introduction of gunpowder.

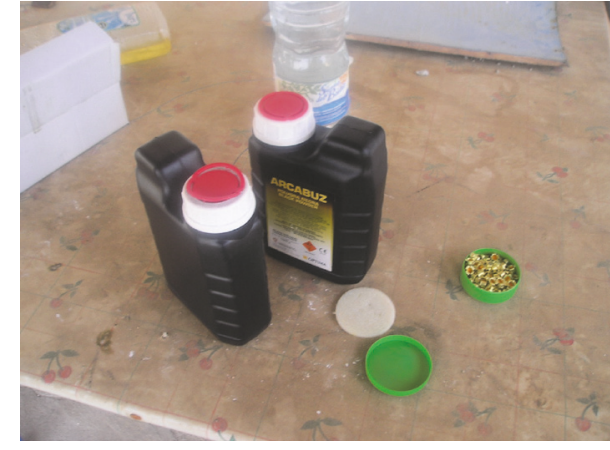

FIGURE 9: Commercial black gunpowder and detonating pistons.

3.3.2. Black Gunpowder. Black gunpowder is a mixture of sulfur, charcoal, and potassium nitrate. It cannot be considered as an explosive because the result of its reaction is in the form of deflagration in detonation. One of the main characteristics of this type of powder is the large volume of gases it produces and the high temperatures it reaches during its combustion. Unlike other explosives, its reaction speed is low and can reach speeds up to $500 \mathrm{~m} / \mathrm{s}$, depending on the caliber of the weapon. The dust of powder is very sensitive, so they are supplied in granulated form after adding graphite (which prevents electrostatic charges). To carry out the tests performed in these experiments, we have used black gunpowder marketed by the company Maxam Outdoors (See Figure 9) whose main features are the following ones:

(i) amount of $\mathrm{KNO}_{3}: 74 \%$

(ii) grain size: From 0.35 to $1.19 \mathrm{~mm}$.

3.3.3. Sound Level Meters and Sensors. The measurements of the noise levels are made with professional sound level meters. In this case, the model Type 2250 has been chosen [17]. This device can be understood as a portable analyzer capable of satisfying all measurement and analysis needs in isolation studies. Its application ranges from the traditional uses of environmental noise assessment to quality control and evaluation of the noise in the workplace of an industrial work. The Bruël \& Kjaer Type 2250 performs Class 1 measurements according to international standards. This device contains a high resolution touch screen that allows easy navigation through the configuration menu to customize predefined templates according to the measurement requirements. The Bruël \& Kjaer Type 2250 has a wide dynamic range that supports high amplitude noise levels and noises that are 


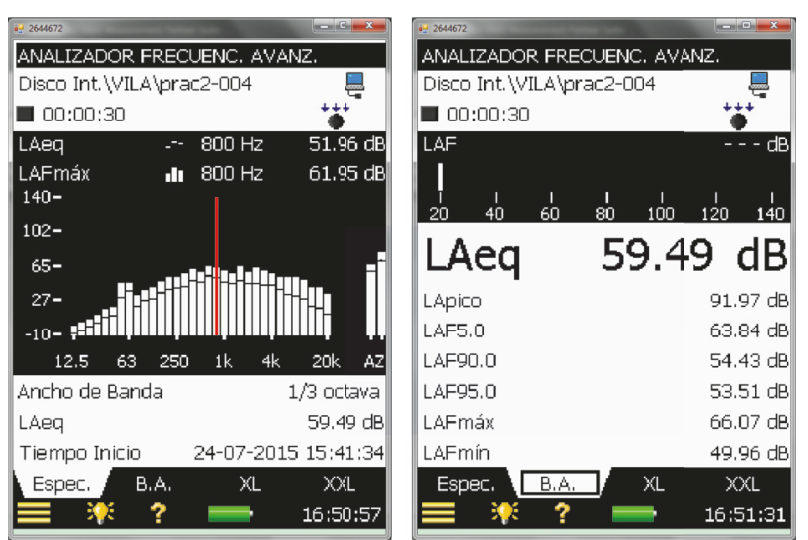

Figure 10: Screenshots of sound level meter Bruël \& Kjaer Type 2250.

only perceived above background noise. It has a fairly large dynamic range between $20 \mathrm{~dB}$ and $140 \mathrm{~dB}$. The device can measure and analyze data in $1 / 1$ octave and $1 / 3$ octave bands. Figure 10 shows some screenshots of this sound level meter that allow the user to visualize the result of the measurements in real time. On the one hand, this sound level meter is able to show measurements in real time; that is, we can move the red cursor along the frequency spectrum and check the levels of sound pressure level as a function of the frequency. We can also see the maximum value registered during the elapsed time. If we move for the next window, we can see a summary of average, minimum, and maximum values as well as the statistical values. This is the average value of sound pressure level registered during the $5 \%, 90 \%$, and $95 \%$ of the measured time.

3.3.4. Accelerometer Used in Scenario 1. The Type 4374 accelerometer is a piezoelectric charge sensor encapsulated in a titanium housing [18]. It has a side connector and integral cable whose function is to connect it to the sound level meter. The Type 4374 sensor must be adhesively attached to the measuring object using beeswax. This accelerometer sensor allows the user to measure high frequency vibration levels in confined spaces and structures where it is difficult to reach. The Type 4374 sensor is based on the piezoelectric element PZ 27 and it is only capable of taking measurements on an axis. This sensor is used in the vibration measurements of scenario 1.

3.3.5. Accelerometer Used in Scenario 2. The accelerometer used in scenario 2 is a Bosch BMA056, 3-axis accelerometer [19] (see Figure 11). This kind of sensor is widely used in smartphones and smart devices because it has very high resolution $\left(0.00390625 \mathrm{~m} / \mathrm{s}^{2}\right)$. It is presented in a very small encapsulation of $3 \times 3 \times 0.95 \mathrm{~mm}^{3}$. The sensor can be measure in the range of $\pm 1000 \mu \mathrm{T}$ (for $x$-, $y$-axis) and $\pm 2500 \mu \mathrm{T}$ (for $z$ axis) with a resolution of $0.3 \mu \mathrm{T}$ and a sensitivity tolerance of $\pm 4 \%$.

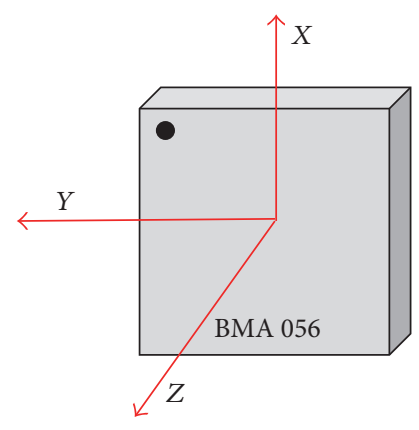

FIGURE 11: Vibration sensor Bosch BMA056- 3-axis accelerometer.

\section{Measurement Results}

Before starting to interpret the measured data, we should take into account a set of considerations about the acoustic measurements.

When we try to measure the noise level, we should know that the frequency weights respond to acoustic sound problems and have a great psychoacoustic component. This occurs because the human ear does not have a flat response for different frequencies based on the same sound pressure; that is, the human ear has a nonlinear frequency response to sounds.

A sound level meter is intended to approximate its responses to the human ear. An acoustic measure that does not consider these psychoacoustic parameters does not accurately reflect the measurements that disturb noisy space compared to human perception. While the sound pressure level (SPL) in $\mathrm{dB}$ describes the physical phenomenon, the weighted decibel level describes the existing volume.

Finally, we would like to point out that our measurements are performed without any kind of weighting, since we do not want to measure the human perception of the noise level produced by the noise sources. In our case, we want to measure the physical effect on the facade and therefore we will use the sound level meters without any weighting; that is, our sound level meter will not apply any equalization as a function of the frequency. This will give us a flat frequency response between $10 \mathrm{~Hz}$ and $20 \mathrm{kHz} \pm 1.5 \mathrm{~dB}$, excluding the microphone response.

The results directly represent the effect we want to measure. All information concerning this type of measurement is presented in the international standard IEC 61672: 2013. Our measurements are carried out in linear weighting (which is equivalent to say that we do not use frequency weights), measured in $\mathrm{dB}$, in the $1 / 3$ octave band [20-22].

4.1. Measurement Results in Scenario 1. To perform the measurements in the first scenario, we used 2 sound level meters. The first one is used to take measurements of the noise level; the second is used to measure the vibrations. The second sound level meter is used together with the 1-axis acceleration piezoelectric sensor (Type 4374), working as a dosimeter. Figure 12 shows the position of these sound level meters while measurements are taken. 


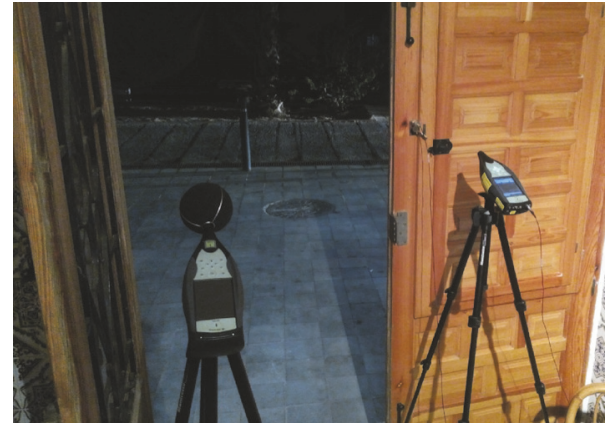

Figure 12: Sound level meters taking measures in Scenario 1.

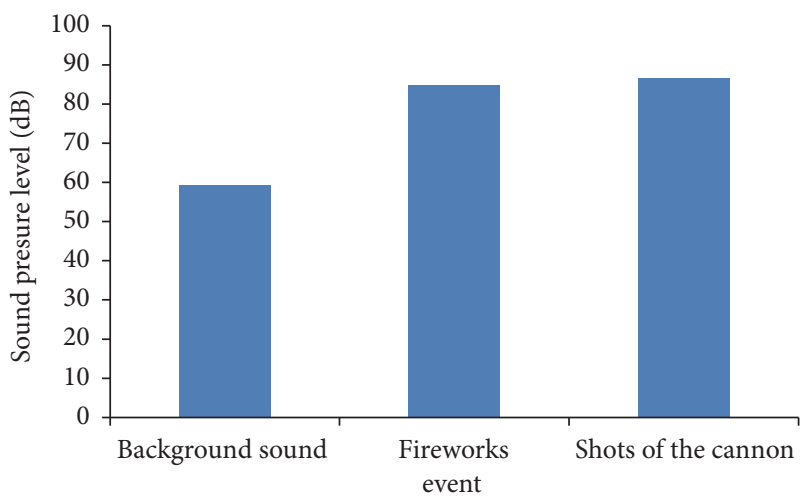

FIGURE 13: Average values of the measures performed for the 3 types of analyzed events.

To start with the measurements of the acoustic impact, it is needed to know the environmental values, that is, the temperature, speed wind, and relative humidity. This is because the acoustic waves are highly affected by them. In addition, when the wind speed is higher than $5 \mathrm{~m} / \mathrm{s}$, the acoustic measurements are not valid [23]. The parameters measured in this place are the following ones:

(i) temperature: $28.2^{\circ} \mathrm{C}$

(ii) relative humidity: $73.3 \%$

(iii) speed wind: $0.4 \mathrm{~m} / \mathrm{s}$.

With these values, we can perform the tests and we will be sure that the recorded values of noise level really represent the effect of the different types of shots performed on the beach.

In order to carry out these measurements, different series of shots every $30 \mathrm{~s}$ are performed during which only the shot or event that we intend to monitor is perceived. After that, we calculate the average value of these measures. Figure 13 shows the average values recorded in scenario 1 . As we can see, the average value of the background noise has a fairly high value (in this case around $60 \mathrm{~dB}$ ). This value, certainly, would not allow an inhabitant of this house to rest. However, considering the type of events celebration, we can consider it as low. In relation to the fireworks and the firing of the weapons, in both cases, the average value of noise is around $85 \mathrm{~dB}$.

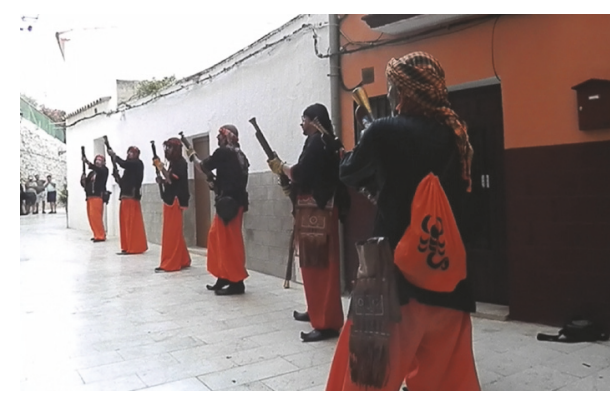

FIGURE 14: Harquebusiers who execute the shots.

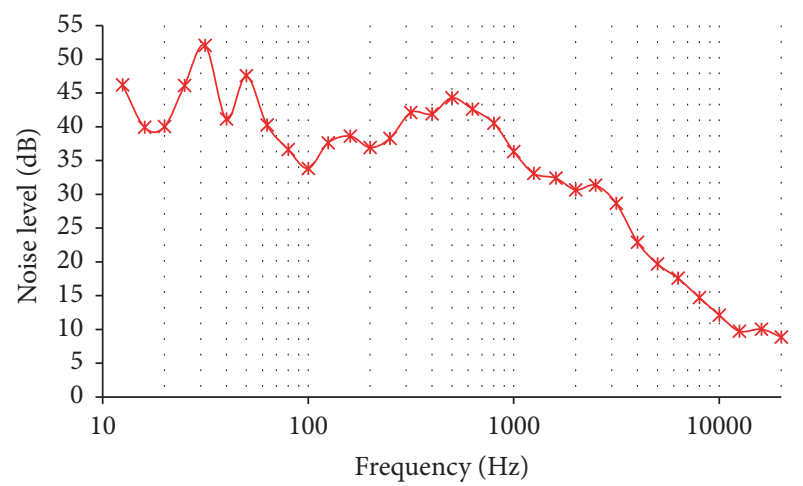

FIGURE 15: Average background sound pressure (in $\mathrm{dB}$ ) registered in the area of shooting.

The vibration value recorded in this test has been negligible. In fact, at sensory level, the people responsible of carrying out the measures did not perceive any type of stimulus or pressure. Therefore, when we took measures on the architectural elements of the building, the result was nil.

4.2. Measurements Results at Scenario 2. First, we measured the environmental conditions. In this case, the environmental conditions measured in the alley were the following ones:

(i) temperature: $29.1^{\circ} \mathrm{C}$

(ii) relative humidity: $75.3 \%$

(iii) speed wind: $1 \mathrm{~m} / \mathrm{s}$.

As the wind speed is much lower than $5 \mathrm{~m} / \mathrm{s}$, we can perform the tests and we will be sure that the registered values of noise level really represent the effect of the harquebuses on the facade. Figure 14 shows the harquebusiers in the alley prepared for firing.

The first step to analyze an acoustic activity is to check the average values of the noise levels received in the facade without the presence of the activity. In our case, the activity is translated into the presence of shots. A total of 3 shots were fired. From these values we have calculated the average value of noise level (in $\mathrm{dB}$ ) recorded on the facade. Figure 15 shows the average value of the background noise level in $\mathrm{dB}$ recorded on the facade. As we observed, the maximum value of noise level is $52.5 \mathrm{~dB}$ at the frequency of $42 \mathrm{~Hz}$. However, we also observed a rather high value $(47.5 \mathrm{~dB})$ compared to 


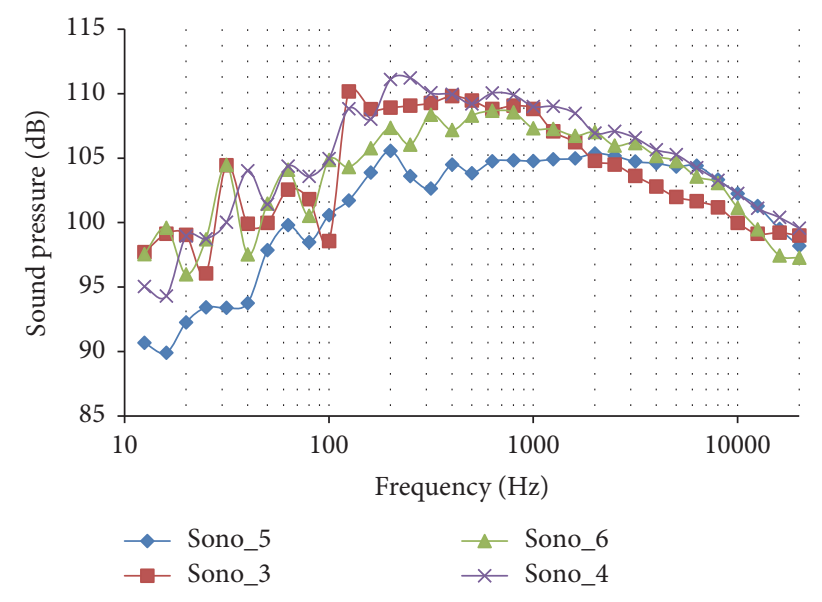

FIgURE 16: Noise level measured by the four sound level meters.

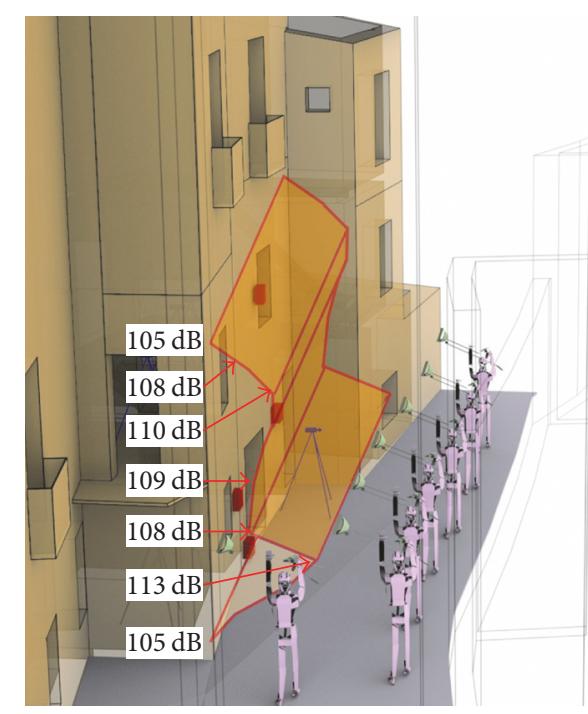

FIGURE 17: Maximum noise levels superposed on the facade.

the rest of the spectrum at $50 \mathrm{~Hz}$. It is easy to conclude that the highest values of noise are located at low frequencies. The range of low frequencies is the one that generates a greater impact on the buildings and, in addition, it generally generates enough discomfort in the people, at the auditory level.

Once the background noise level is measured, we should measure the vibroacoustic impact that firing these weapons generate on the facade. Figure 16 shows the noise level measured by the four sound level meters. As we can see, the sound level meter closest to the ground floor (Sono_5) records the lowest noise level, with $105 \mathrm{~dB}$, while Sono_3 and Sono_4 record values close to $110 \mathrm{~dB}$. In all cases, the highest noise impact has been recorded in the range of $100-250 \mathrm{~Hz}$, which can be considered as low frequencies.

Finally, in order to see more clearly the point where a greater acoustic impact is perceived, in Figure 17 we overlap the maximum values of noise level registered in each point of the facade at $310 \mathrm{~Hz}$ over the image of the facade. As we

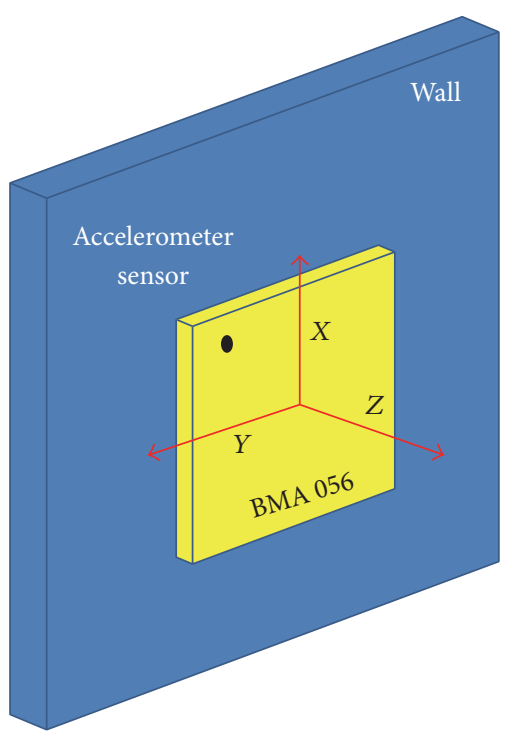

Figure 18: Position of the accelerometer on the facade.

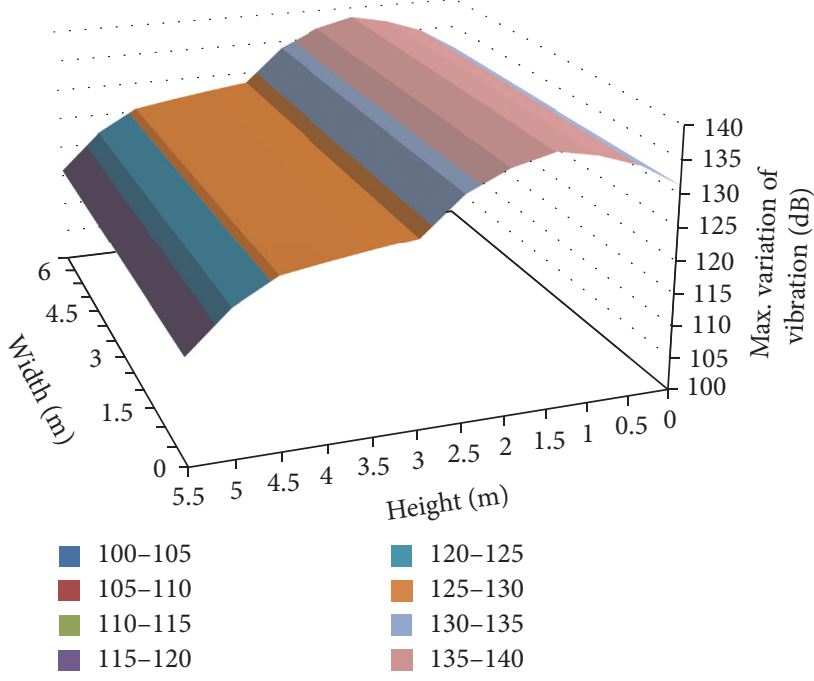

FIGURE 19: Variation of vibration in $\mathrm{dB}$ for $z$-axis.

can see, there are 2 points where the highest noise levels are received. The first one is located at the harquebusiers height (around $1.5 \mathrm{~m}$ ) and the second one is located at $4.5 \mathrm{~m}$ height.

In order to record the movements and vibrations generated in the building by the effect of the acoustic wave impacting the facade, we used 3-axis accelerometers. These devices give us information about the movements generated in the building for the $X$-, $Y$ - and $z$-axes. However, the most important variation will be recorded on the $z$-axis due to the position we have placed the sensors on the wall (see Figure 18). We have processed the vibration values individually for each axis.

Figures 19, 20, and 21 show the vibration map on the facade for the $z$-axis, the $y$-axis, and the $x$-axis, respectively. The highest vibrations are recorded on the $z$-axis (see Figure 19). In addition, the highest value is recorded around 


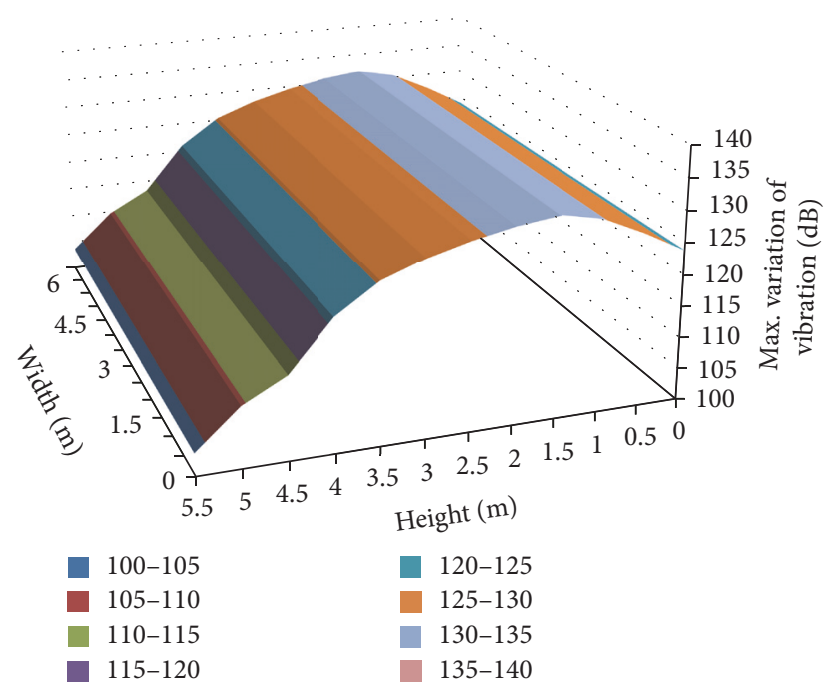

FIGURE 20: Variation of vibration in $\mathrm{dB}$ for $y$-axis.

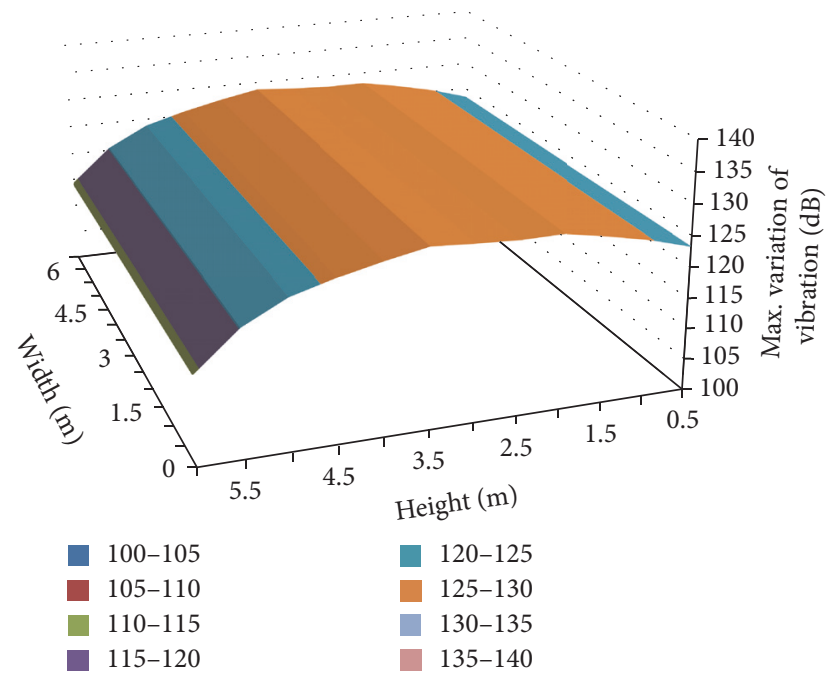

FIGURE 21: Variation of vibration in $\mathrm{dB}$ for $x$-axis.

$1.5 \mathrm{~m}$, with maximum value of $138 \mathrm{~dB}$ which corresponds to the height at which the harquebuses generate the highest noise level. The axis that registers the lowest vibration is the $x$-axis, with a maximum value of $130 \mathrm{~dB}$ at $3.5 \mathrm{~m}$. height.

As we can see the axis that suffers the greatest vibration is the $z$-axis. Since acceleration is a vectorial magnitude, it can be measured in the three Cartesian coordinates, as we represented in Figures 19, 20, and 21. However, we can also show the combination of three axes in order to see the magnitude. Figure 22 shows the combined vibration level of three axes as a function of the facade height. Showing these results, we can see that the biggest vibration is registered at $1.5 \mathrm{~m}$ height.

In order to see more clearly which points of the facade recorded major movements or vibrations, we superimpose the values given in Figure 19 on the facade. Figure 23 shows the levels of vibration on the facade. In this way, we can see that the part where the greatest vibration occurs is just the

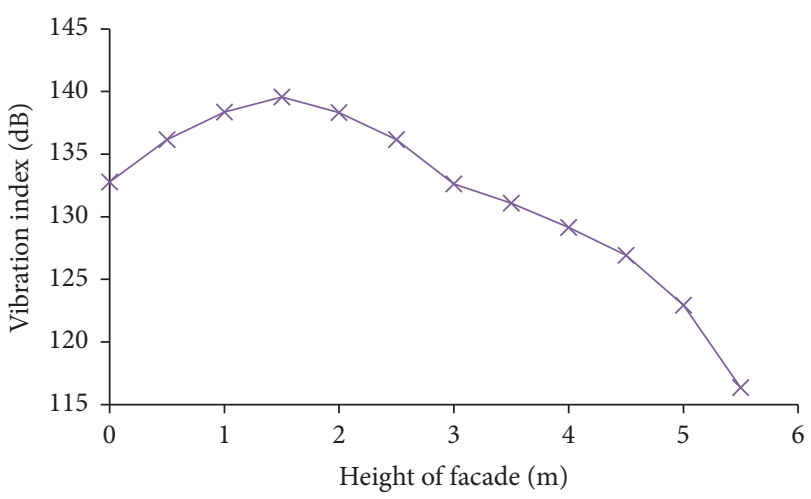

Figure 22: Variation of vibration in $\mathrm{dB}$ for $x$-axis.

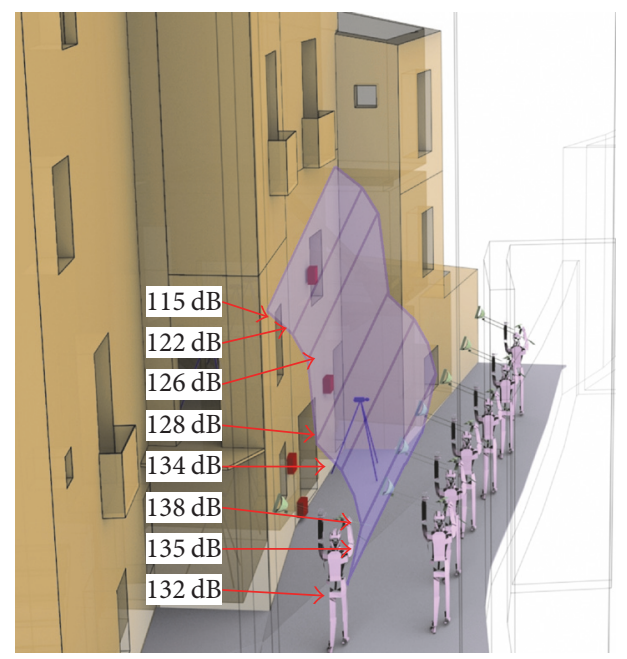

FIGURE 23: Maximum vibration values recorded on the facade.

one that corresponds with the ground floor, with a value close to $140 \mathrm{~dB}$. Then, we can observe a flatter zone with vibration values close to $126-128 \mathrm{~dB}$ and finally the vibrations are attenuating as the height increases.

\section{Conclusion}

In the Spanish Mediterranean coast, during the summer season, we can find several festivals that commemorate historical events such as wars and reconquest of lost territories. During these festivals the ancient battles are replicated along the historical center of the cities. Generally, these recreations are companied with pyrotechnics. The European countries are the ones that conserve the major number of historical buildings such as fortresses, watchtowers, churches, and historic facades that are placed in the historical center of the cities. However, there is no study published specifying the repercussion of these recreations over these buildings.

Due to the need of keeping our architectonical heritage, in this paper, we have presented a practical study about the vibroacoustic impact that different kind of pyrotechnic can generate over these buildings. In order to perform out a practical study, we used 2 different scenarios, that is, a house 
placed on the beach and an old house located in a narrow alley. The measurements have been performed during the festival of Moors and Christians of Villajoyosa (in Alicante province, Spain) which is famous for this festival. In both cases, several sound level meters and vibration sensors have been placed to gather the data.

The results have shown that the celebrations placed in the beach present a very low effect over the dwelling because the effect of the acoustic waves was not perceived as vibration. However, the results shown in the narrow alley were clearly perceived as vibrations and had very high noise level. We have observed that the greatest acoustic impact is recorded at $1.5 \mathrm{~m}$ height (with $113 \mathrm{~dB}$ ), although it also recorded a high noise level at $4.5 \mathrm{~m}$ height (with $110 \mathrm{~dB}$ ). Regarding the vibration results, we have seen that the facade generates greater vibrations in the $z$-axis at $1.5 \mathrm{~m}$. height, with values around $138 \mathrm{~dB}$. So, there are clearly 2 areas with the greatest impact of sound pressure. This is because, during a shot, the explosion generated by the weapon has approximately been generated at 1.5-2 $\mathrm{m}$ height, that is, the height where we can find the weapon handle and the trigger, while the deflagration can reach several meters (up to 5-6 m) height and also causes the propagation of sound waves.

These results show that the vibroacoustic effect on the facade claddings in a bad state is high and is capable of causing detachment and human injuries. The determination of human injuries, rather than the built heritage, can be decisive for limiting these traditional celebrations in historic centers of cities and towns.

Because we have verified that the vibroacoustics effects registered in the housing of the beach do not cause an appreciable impact on the buildings, as future work we would like to perform a more exhaustive study on the house located in the narrow alley. Moreover, we would also like to focus our study on other architectural elements by implementing a wireless sensor network [6] to perform long series of measurements simultaneously in several buildings and combine the results using distributed database management techniques $[24,25]$.

\section{Conflicts of Interest}

The authors declare that there are no conflicts of interest regarding the publication of this paper.

\section{References}

[1] G. J. Ashworth and P. J. Larkbam, Building a New Heritage: Tourism, Culture and Identity in the New Europe, Routledge Library Editions: Tourism, 1st edition, 2013.

[2] M. Crang, "Building a new heritage: tourism, culture and identity in the New Europe," Journal of Rural Studies, vol. 12, no. 2, pp. 206-207, 1996.

[3] S. Sendra, J. Lloret, M. García, and J. F. Toledo, "Power saving and energy optimization techniques for wireless sensor networks," Journal of Communications, vol. 6, no. 6, pp. 439-459, 2011.

[4] S. Sendra Compte, Deployment of Efficient Wireless Sensor Nodes for Monitoring in Rural, Indoor and Underwater Environments, Universitat Politècnica de València, 1st edition, 2013.
[5] M. Garcia, D. Bri, S. Sendra, and J. Lloret, "Practical deployments of wireless sensor networks: a survey," International Journal on Advances in Networks and Services, vol. 3, no. 1-2, pp. 170-185, 2010.

[6] S. Sendra, A. T. Lloret, J. Lloret, and J. J. P. C. Rodrigues, "A wireless sensor network deployment to detect the degeneration of cement used in construction," International Journal of Ad Hoc and Ubiquitous Computing, vol. 15, no. 1-3, pp. 147-160, 2014.

[7] N. Kurata, B. F. Spencer Jr., and M. Ruiz-Sandoval, "Risk monitoring of buildings using wireless sensor network," in Proceedings of the International Workshop on Advanced Sensors, Structural Health Monitoring, and Smart Structures, pp. 10-11, Tokyo, Japan, November 2003.

[8] F. D’Amato, P. Gamba, and E. Goldoni, "Monitoring heritage buildings and artworks with wireless sensor networks," in Proceedings of the 3rd IEEE Workshop on Environmental, Energy, and Structural Monitoring Systems (EESMS '12), pp. 1-6, Perugia, Italy, September 2012.

[9] J. Lloret, A. Canovas, S. Sendra, and L. Parra, "A smart communication architecture for ambient assisted living," IEEE Communications Magazine, vol. 53, no. 1, pp. 26-33, 2015.

[10] H. Ghayvat, S. Mukhopadhyay, X. Gui, and N. Suryadevara, "WSN- and IOT-based smart homes and their extension to smart buildings," Sensors, vol. 15, no. 5, pp. 10350-10379, 2015.

[11] S. H. Park, P. J. Lee, K. S. Yang, and K. W. Kim, "Relationships between non-acoustic factors and subjective reactions to floor impact noise in apartment buildings," Journal of the Acoustical Society of America, vol. 139, no. 3, pp. 1158-1167, 2016.

[12] J. Marco Sanjuán, "Estudios del nivel sonoro de diferentes tipos de pólvoras negras para arcabuces y trabucos de salvas," Revista Especial Día 4 que Fuera de la Junta Central de Fiestas de Villena, 1996, http://server-die.alc.upv.es/Alcoy/Tuna/interest .htm.

[13] P. J. Bennett, K. Soga, I. Wassell et al., "Wireless sensor networks for underground railway applications: Case studies in Prague and London," Smart Structures and Systems, vol. 6, no. 5-6, pp. 619-639, 2010.

[14] M. Späh, K. Hagberg, O. Bartlomé, L. Weber, P. Leistner, and A. Liebl, "Subjective and objective evaluation of impact noise sources in wooden buildings," Building Acoustics, vol. 20, no. 3, pp. 193-213, 2013.

[15] C.-J. Yu and J. Kang, "Environmental impact of acoustic materials in residential buildings," Building and Environment, vol. 44, no. 10, pp. 2166-2175, 2009.

[16] J. Klos, "Vibro-acoustic response of buildings due to sonic boom exposure: July 2007 field test," Reference Document NASA/TM2008-215349, 2008, http://ntrs.nasa.gov/archive/nasa/casi.ntrs .nasa.gov/20080037572.pdf.

[17] Sound Level Meter Bruël \& Kjaer Type 2250 features, Bruël \& Kjaer, https://www.bksv.com/en/products/sound-and-vibrationmeters/sound-level-meters-and-vibration-meters/Type-2250-S.

[18] Características del sensor de vibracion Type 4374, http://pdf .directindustry.es/pdf-en/bruel-and-kjaer/transducers-conditioning/17114-692236.html\#open.

[19] Características del sensor de vibracion Bosch BMA0563 axis accelerometer, https://www.bosch-sensortec.com/bst/ products/all_products/bmc056.

[20] IEC 61672-1:2013-Electroacoustics-Sound level meters-Part 1: Specifications, https://webstore.iec.ch/publication/5708.

[21] IEC 61672-2:2013-Electroacoustics-Sound level meters-Part 2: Pattern evaluation tests, https://webstore.iec.ch/publication/ 5709. 
[22] IEC 61672-3:2013-Electroacoustics-Sound level meters-Part 3: Periodic tests, https://webstore.iec.ch/publication/5710.

[23] C. Harris, Manual de Medidas Acusticas y Control del Ruido, S.A. Mcgraw-Hill/Interamericana De España, 3rd edition, 1995.

[24] O. Diallo, J. J. P. C. Rodrigues, M. Sene, and J. Lloret, "Distributed database management techniques for wireless sensor networks," IEEE Transactions on Parallel and Distributed Systems, vol. 26, no. 2, pp. 604-620, 2015.

[25] N. Meghanathan, "A generic algorithm to determine maximum bottleneck node weight-based data gathering trees for wireless sensor networks," Network Protocols and Algorithms, vol. 7, no. 3, pp. 18-51, 2015. 


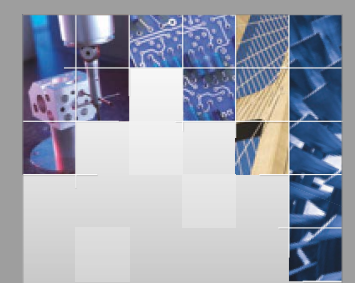

\section{Enfincering}
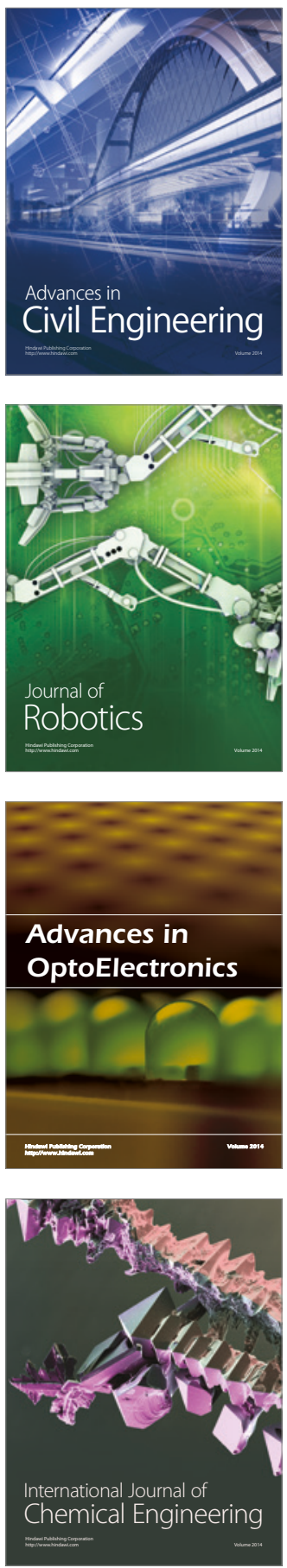

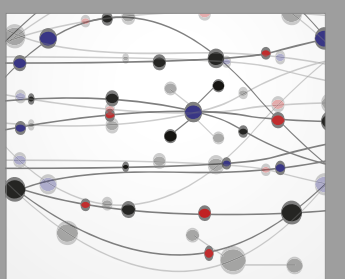

The Scientific World Journal

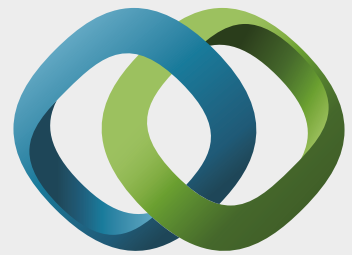

\section{Hindawi}

Submit your manuscripts at

https://www.hindawi.com
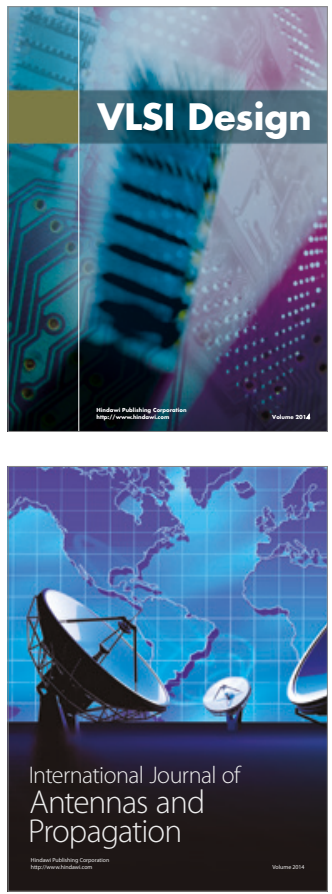

\section{Rotating}

Machinery
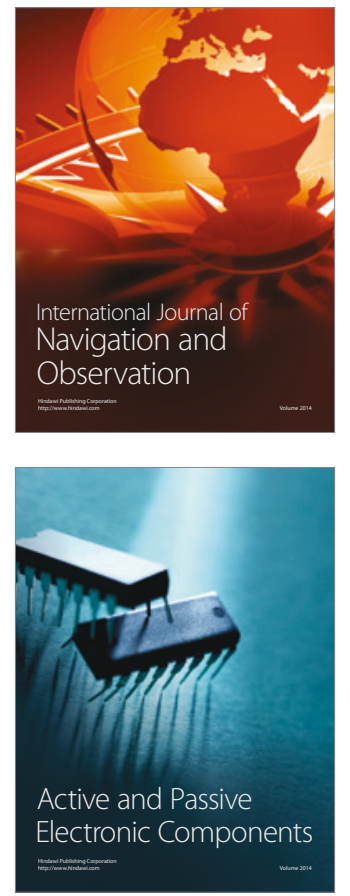
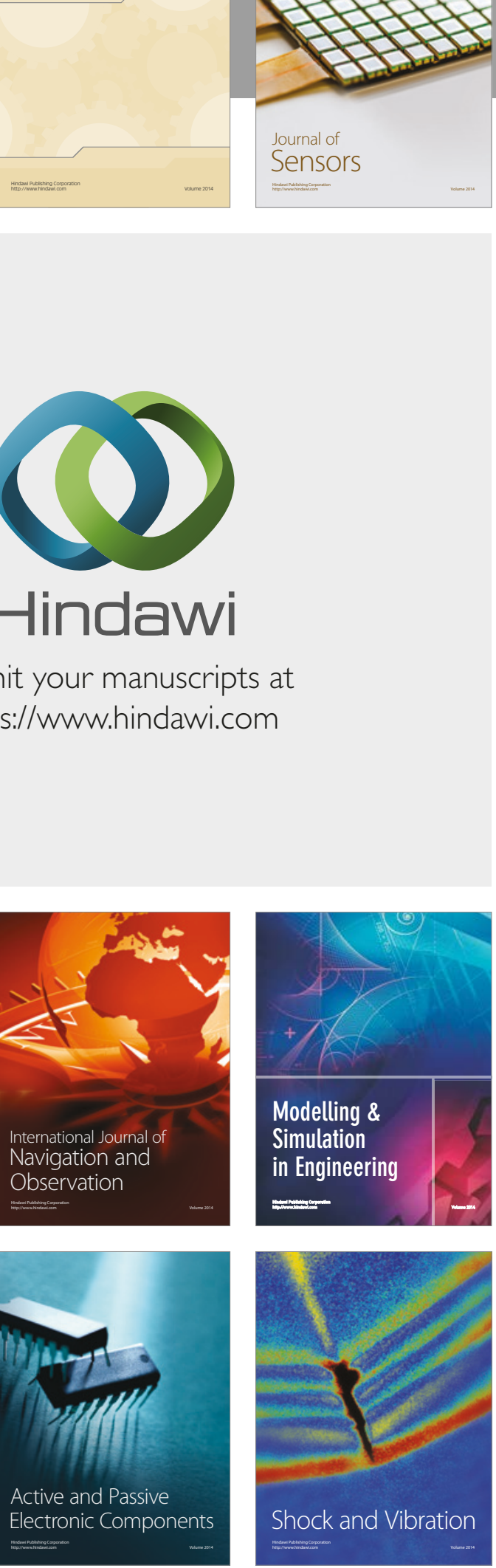
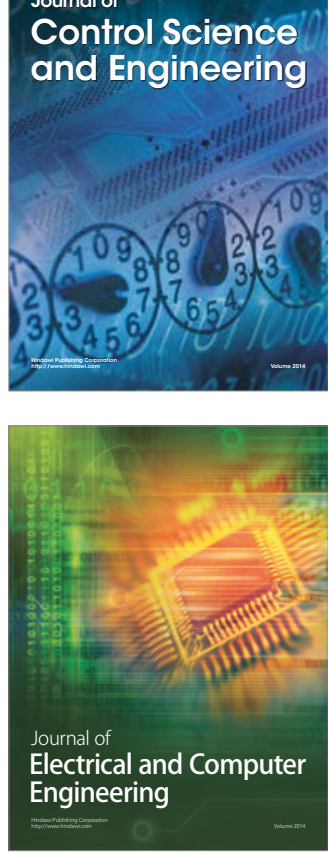

Distributed

Journal of

Control Science

and Engineering
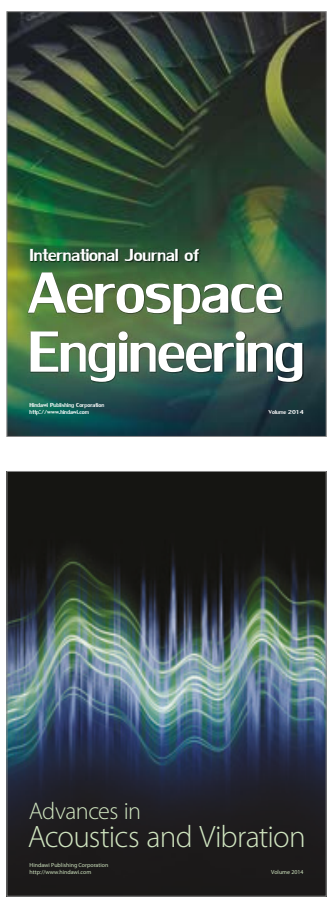

Sensor Networks 